Article

\title{
Divide et impera: an in silico screening targeting HCMV ppUL44 processivity factor homodimerization identifies small molecules inhibiting viral replication
}

\author{
Hanieh Ghassabian ${ }^{1}$, Federico Falchi ${ }^{2}$, Martina Timmoneri ${ }^{1}$, Beatrice Mercorelli ${ }^{1}$, Arianna \\ Loregian $^{1}$, Giorgio Palù ${ }^{1}$, Gualtiero Alvisi ${ }^{*}$ \\ 1 Department of Molecular Medicine, University of Padua, Italy; haniehghassabian@gmail.com; \\ hanieh.ghassabian@unipd.it; martina.timmoneri@gmail.com; beatrice.mercorelli@unipd.it; \\ arianna.loregian@unipd.it; giorgio.palu@unipd.it; gualtiero.alvisi@unipd.it \\ 2 Molecular Horizon, Bettona (PG), Italy federico.falchi@hotmail.com \\ * Correspondence: gualtiero.alvisi@unipd.it;
}

\begin{abstract}
Human cytomegalovirus (HCMV) is a leading cause of severe diseases in immunocompromised individuals, including AIDS and transplanted patients, and in congenitally infected newborns. The utility of available drugs is limited by poor bioavailability, toxicity, and emergence of resistant strains. Therefore, it is crucial to identify new targets of therapeutic intervention. Among the latter, viral protein-protein interactions are becoming increasingly attractive. Since dimerization of HCMV DNA polymerase processivity factor ppUL44 plays an essential role in the viral life cycle being required for oriLyt-dependent DNA replication, we performed an in silico screening and selected 18 small molecules (SMs) potentially interfering with ppUL44 homodimerization. Antiviral assays using recombinant HCMV TB40-UL83-YFP in the presence of the selected SMs led to the identification of four active compounds. The most active one, B3, also efficiently inhibited AD169 in plaque reduction assays and impaired replication of an AD169-GFP reporter virus and its ganciclovir-resistant counterpart to a similar extent. As assessed by Western blotting experiments, treatment of infected cells with B3 specifically reduced viral gene expression starting from $48 \mathrm{~h}$ post infection, consistent with activity on viral DNA synthesis. Therefore, inhibition of ppUL44 dimerization could represent a new class of HCMV inhibitors, complementary to those targeting the DNA polymerase catalytic subunit or the viral terminase complex.
\end{abstract}

Keywords: HCMV; protein-protein interactions; small molecules; ppUL44; PAP; pUL54; antivirals; screening.

\section{Introduction}

The $\beta$-Herpesvirinae member human cytomegalovirus (HCMV) is a major human pathogen, causing severe and life-threatening infections in immunocompromised patients [1] and in congenitally infected newborns [2]. Herpesviruses are opportunistic double-stranded DNA viruses, whose genome transcription, replication, and packaging occur in the host cell nucleus [3]. The molecular mechanisms involved in herpesvirus DNA replication and its regulation have been widely studied as they provide important models for the study of eukaryotic DNA replication and because viral enzymes involved in the process represent targets for antiviral therapy. HCMV DNA polymerase holoenzyme is a multi-functional enzyme that plays a key role during viral infection ensuring replication of the viral genome, and consists of the catalytic subunit pUL54 and the processivity factor ppUL44 [4]. Not surprisingly, the most widely antiviral agents used to fight HCMV infections target pUL54 and are either nucleoside or pyrophosphate analogues such as ganciclovir (GCV) or foscarnet (PAA), respectively [5]. However, long-term administration of these antiviral agents frequently leads to the selection of viral isolates with reduced drug susceptibility, due to mutations on either pUL54 or on pUL97, the viral kinase phosphorylating GCV $[6,7]$. Treatment with the recently approved 
Letermovir, which targets the viral terminase complex $[8,9]$, has been similarly shown to cause the selection of viral resistant strains [10, 11]. Therefore, there is a recognized need for novel anti-HCMV compounds that target other viral functions.

ppUL44 is a 52-KDa protein essential for viral replication which binds to dsDNA and directly interacts with pUL54, stimulating its activity by tethering the DNA polymerase holoenzyme to the DNA template [12-15]. ppUL44 can be functionally and structurally divided in an N-terminal (residues 1-290) and a C-terminal domain (residues 291-433). The N-terminal domain has been successfully crystallized and retains all known ppUL44 biochemical properties [15, 16]. However, the C-terminal domain, responsible for ppUL44 transactivation properties and its phosphorylationdependent nuclear transport, is absolutely required for virus replication [17-21]. ppUL44(1-290) adopts a $C$ clamp-shaped structure and forms head-to-head dimers, wherein each monomer forms two topologically similar domains that share a central $\beta$-sheet and are connected by a long connector loop responsible for binding to pUL54 [22, 23]. The dimerization involves interaction of six mainchain-to-main-chain hydrogen bonds and extensive packaging of hydrophobic side chain at the interface and results in the formation of a central cavity, able to accommodate the viral DNA [24]. Indeed, the ppUL44-dsDNA interaction depends on electrostatic interactions between the dsDNA backbone and basic residues located both on the central cavity and on a highly flexible gap loop not visible in the published crystal structure [24, 25]. Accordingly, the substitution of specific hydrophobic residues at the homodimerization interface of ppUL44(1-290) sufficient to impair dimerization, also reduces the DNA binding affinity of ppUL44 in vitro [16]. Recent studies showed that dsDNA binding of ppUL44 is essential for HCMV DNA replication, as in the case of herpes simplex virus-1 (HSV-1) [26]. Indeed, substitution of either basic gap loop residues, or of residues at the dimerization interface such as L86 and L87, which make extensive contacts with the hydrophobic residues along the dimer interface [16], caused a dramatic alteration of ppUL44 subcellular localization and DNA binding in cells, and completely abolished the ability of ppUL44 to transcomplement oriLyt dependent DNA replication [23, 25, 27]. Therefore, ppUL44 dimerization is important to stabilize the interaction between pUL54 catalytic subunit and DNA and an alteration of this dimerization may block DNA synthesis and HCMV replication [28]. In this context, ppUL44 dimerization thus emerges as a potential target for the development of novel antiviral approaches.

Protein-protein interactions (PPIs) are essential to all biological processes and can be modulated by small molecules [29-31], thus representing a large class of therapeutic targets and implying the possibility to impair viral replication and pathogenesis [32-34]. Several inhibitors have reached the clinical trials thanks also to the development of computational and chemical technologies, alongside with experimental and virtual fragment screens used to define the druggability of PPIs [35, 36]. Most of such inhibitors target PPIs in which partner proteins are characterized by short primary sequences at the interface $[37,38]$ and the hot-spots residues are concentrated in small binding pockets $[39,40]$. Recent studies have also reported the inhibition of protein dimerization, with a focus on proteins overexpressed in cancer or involved in viral replication [30, 41-43].

In this study, we aimed at identifying small molecules (SMs) that can hinder HCMV replication by interfering with ppUL44 homodimerization. To this end, we used the ppUL44 homodimer structure as a template to screen about 1.3 million SMs from the ZINC database to identify 18 SMs potentially able to interfere with ppUL44 homodimerization via an in silico screening. Our results clearly showed that one out of the 18 SMs tested (i.e., SM B3) could inhibit different HCMV strains, including a GCVresistant strain, as assessed by plaque reduction, fluorescence reduction, and virus yield reduction assays. Finally, SM B3 affected HCMV gene expression only starting from $48 \mathrm{~h}$ post infection (p.i.), causing a strong decrease of late gene pp28 expression at $72 \mathrm{~h}$ and $96 \mathrm{~h}$ p.i. Therefore, our results are consistent with a specific inhibitory effect of B3 on viral DNA replication. 


\section{Materials and Methods}

2.1 Analysis of ppUL44 dimerization interface. The crystallographic structure of ppUL44 homodimer [16] was downloaded from the Protein Data Bank (pdb code: 1T6L). Only the A chain was extracted from the complex. The structure was optimized with the Protein Preparation Wizard tool of the Schrodinger suite (Schrödinger). The research of potentially druggable sites at the dimerization interface of ppUL44(1-290) was assessed with software Sitemap [44], using default settings apart from grid resolution which was set as fine.

2.2 Virtual screening database preparation. A 3D molecular database was built with the Schrodinger suite (Schrödinger) starting from 2D structures taken from the ZINC database (www.zinc.docking.org). A total number of about 3.6 million compounds were selected (Vendors: Asinex, Chembridge, Princeton, NCI and ZINC natural) and downloaded for this study. 2D structures were converted into 3D structures and stereoisomers were generated with the Ligprep function of the Schrodinger suite (Schrödinger). Moreover, for each entry all the possible ionization states at $\mathrm{pH} 7.0 \pm 2.0$ and tautomers were generated with Epik (Schrödinger). The obtained database consisted of about 5 million compounds. In order to retrieve the most drug-like compounds, ADMET properties of each molecule in the database were predicted with Qikprop (Schrödinger) and compounds were filtered as described in [45] using a "soft Lipinsky rule" (Molecular weight $\leq 600$, Rotable bonds $\leq 10$, Number of H-bond acceptors $\leq 10$, Number of H-bond donors $\leq 5$, Number of chiral centers $\leq 2$, QplogPo/w $\leq$ 6). Finally, the number of compounds was reduced to about 1.3 million by using the PPI-HitProfiler software with the "soft" mode (CDithem; http://www.cdithem.fr).

2.3 Virtual screening. For the docking stage, a receptor grid was built on the ppUL44 structure prepared as above. The grid was centered on the position of residue M116 and receptor grid generation default settings were applied. By using this grid, the database was docked with the High throughput virtual screening (HTVS) scoring function of the Glide software (Schrödinger). After this run, we selected 50,000 compounds on the basis of the HTVS docking score. Selected molecules were submitted to a second run of docking using the standard precision (SP) scoring function and only the 5,000 top-ranked compounds were selected. Finally, selected molecules were submitted to a run of docking using the extra precision (XP) scoring function and only the 500 top-ranked compounds were selected. After docking, we further narrowed down the number of selected compounds to 18 on the basis of commercial availability, visual inspection, and by a cluster analysis performed with Tanimoto on the basis of the Molprint2D fingerprints of each molecule [46].

2.4 Antiviral compounds testing. For identification of small molecules (SMs) active on HCMV replication, MRC5 cells $(1.5 \times 104$ cells/well) were seeded in 96-well special optics black microplates (Corning, CLS3614) and incubated overnight at $37^{\circ} \mathrm{C}, 5 \% \mathrm{CO} 2$ and $95 \%$ humidity. The next day, cells were infected for $1 \mathrm{~h}$ at $37^{\circ} \mathrm{C}$ in $100 \mu \mathrm{l} /$ well of DMEM containing TB4-UL83-EYFP at an MOI of 0.03 infectious units (IU)/cell. Cells were subsequently washed, and media containing either $0.5 \%$ DMSO or two different concentrations $(100$ and $10 \mu \mathrm{M})$ of SMs with a $0.5 \%$ DMSO final concentration was added. $50 \mu \mathrm{M} \mathrm{GCV}$ was included as a positive control for inhibition of viral replication. Mock infected cells served as a reference for calculation of background fluorescence. After addition of SMs, the plates were further incubated at $37^{\circ} \mathrm{C}, 5 \% \mathrm{CO}_{2}$ and $95 \%$ humidity. Every day, cell confluence and morphology, as well as CPE and the presence of precipitates were evaluated by light microscopy. Fluorescence signals were visualized on an inverted fluorescent microscope (Leica, DFC420 C). Seven days p.i., cells were washed once with PBS and lysed with luciferase lysis buffer $(25 \mathrm{mM}$ glycylglycine, $15 \mathrm{mM} \mathrm{MgSO} 4,4 \mathrm{mM}$ EGTA, $0.1 \%$ Triton X-100, pH 7.8). Plates were immediately frozen at $-20^{\circ} \mathrm{C}$, thawed at $\mathrm{RT}$, and fluorescent signals relative to each condition were acquired using a reader compatible with fluorescence measurements (VICTOR X2 Multilabel Plate Reader, Perkin Elmer) equipped with a fluorimetric excitation filter (band pass $485 \pm 14 \mathrm{~nm}$ ) and a fluorimetric emission filter (band pass $535 \pm 25 \mathrm{~nm}$ ). After background subtraction, data were normalized to solvent-treated controls and analyzed with Graphpad Prism (Graphpad Software Inc.). The screening 
was performed three times, and each plate included at least two wells treated with the same compound, as well as at least 12 wells treated with solvent only.

2.5 Fluorescence reduction assays (FRA). To calculate the effective dose 50 (ED50) of each compound against TB4-UL83-EYFP virus by means of FRA, MRC5 cells were seeded, infected, treated, and processed as above, using increasing concentrations of each SMs and GCV (range between 0.02 and $100 \mu \mathrm{M})$. Mock infected cells served as a reference for calculation of background fluorescence. After background subtraction, data were normalized to solvent-treated controls and analyzed with Graphpad Prism (Graphpad Software Inc.). The experiments were performed six times, and each plate comprised at least two wells treated with the same compound, as well as at least 14 wells treated with solvent only. To calculate the ED50 of each compound against AD169-GFP virus and its GCVresistant AD169-GFP26 counterpart by the means of FRA, MRC5 cells were seeded in 12-well plates $(1.8 \times 105$ cells/well) in $1 \mathrm{ml}$ DMEM supplemented with $10 \%(\mathrm{v} / \mathrm{v}) \mathrm{FBS}, 50 \mathrm{U} / \mathrm{ml}$ penicillin, $50 \mathrm{U} / \mathrm{ml}$ streptomycin and $2 \mathrm{mM} \mathrm{L}$-glutamine, and incubated overnight at $37^{\circ} \mathrm{C}, 5 \% \mathrm{CO} 2$ and $95 \%$ humidity. The next day, cells were infected for $2 \mathrm{~h}$ at $37{ }^{\circ} \mathrm{C}$ in $1 \mathrm{ml} /$ well of DMEM at MOI of $0.05 \mathrm{IU} / \mathrm{cell}$ as described in [47]. Subsequently, cells were washed with $2 \mathrm{ml}$ of PBS, and $1 \mathrm{ml}$ of medium containing either $0.5 \%$ DMSO or increasing concentrations (from 0.001 to $100 \mu \mathrm{M}$ ) of each compound with a $0.5 \%$ DMSO final concentration was added. Every day, cell confluence and morphology, as well as CPE and the presence of precipitates were evaluated by light microscopy, whereas fluorescence signals were visualized on an inverted fluorescent microscope (Leica, DFC420 C). Seven days p.i., supernatants were collected, cleared from cells and debris by centrifugation for 5' at $700 \mathrm{rpm}$, and stored at $-80^{\circ} \mathrm{C}$ until used for virus yield reduction assays (VYRAs) as described below. Cells were washed with $2 \mathrm{ml}$ of ice cold PBS and lysed in $200 \mu \mathrm{l}$ of GFP lysis buffer $(25 \mathrm{mM}$ Tris-HCl, $\mathrm{pH} 7.8,2$ $\mathrm{mM}$ DTT, $2 \mathrm{mM}$ trans-1,2-diaminocyclohexane- $\mathrm{N}, \mathrm{N}, \mathrm{N}, \mathrm{N}$-tetraacetic acid, $1 \%$ Triton $\mathrm{X}-100,10 \%$ glycerol $[\mathrm{v} / \mathrm{v}])$. Plates were further incubated $10^{\prime}$ at $37^{\circ} \mathrm{C}$ in a humidified incubator, before being incubated for $30^{\prime}$ at RT with shaking at $225 \mathrm{rpm}$. Samples were centrifuged for $5^{\prime}$ at $4^{\circ} \mathrm{C}$ at $13,000 \mathrm{rpm}$ and $100 \mu \mathrm{l}$ of cleared lysates were transferred to black bottomed 96-well plates (Costar, \#3916). Fluorescent signals were acquired and analyzed as described above.

2.6 Virus yield reduction assays (VYRAs). To determine the $\mathrm{ED}_{50}$ of each compound against AD169-GFP virus and its GCV-resistant AD169-GFP26 counterpart by the means of VIAs, MRC5 cells were seeded in clear flat bottom 96 -well tissue culture plates $\left(1.5 \times 10^{4}\right.$ cells/well) with low evaporation lids (Falcon, \#353072). The next day, medium was replaced with serial dilutions of supernatants containing AD169-GFP or AD169-GFP26 virus grown in the presence of inhibitory compounds. One week later, virus yield relative to each condition was calculated and expressed as 50\% Tissue Culture Infectious Dose $\left(\mathrm{TCID}_{50}\right) / \mathrm{ml}$ using the Spearman and Karber algorithm as described in [48].

2.7 Plaque reduction assays (PRA). The effect of B3 and GCV on AD169 replication in human foreskin fibroblast (HFF) cells was investigated by plaque reduction assays as previously described [49]. Please see Appendix A for further details.

2.8 Cell cytotoxicity assays. To evaluate the effect of SMs on cell viability and proliferative potential, two separate assays were performed. MTT assays, which measure $\mathrm{NAD}(\mathrm{P}) \mathrm{H}$-dependent oxidoreductase enzymes and CellTiter-Glo ${ }^{\circledR}$ Luminescent Cell Viability Assay assays, which measure intracellular ATP. See Appendix A for further details.

2.9 Analysis of HCMV gene expression by Western Blotting. MRC5 cells were seeded on 6-well flat bottom plates (6×105/well) with low evaporation lid (Falcon, \#353046). The following day, cells were either mock infected or infected with HCMV (strain AD169) at MOI of $2 \mathrm{IU} / \mathrm{cell}$ in DMEM at $37^{\circ} \mathrm{C}$. One hour p.i., cells were washed twice with PBS and medium containing either solvent only ( $0.5 \%$ DMSO), $\mathrm{GCV}$, or B3 at a concentration 6 times the $\mathrm{ED}_{50}$ as calculated for AD169-GFP in FRAs $(16$ or $50 \mu \mathrm{M}$, respectively), was added to each well. At different times p.i., cells were processed for SDS page/Western blotting as described previously [50] to detect viral antigens. Chemioluminescent 
signals were acquired using an imaging system (Alliance Mini, Uvitech) and quantified using Image J (NIH). See Appendix A for further details.

\section{Results}

3.1 An in-silico screening identifies small molecules potentially interfering with ppUL44 dimerization. We aimed at identifying small molecules (SMs) interfering with ppUL44 self-interaction. To this end, the published crystal structure of ppUL44 (Figure 1A) was analyzed with SiteMap to identify top-ranked potential receptor binding sites on the protein monomer. Our analysis identified 3 sites as potential receptor binding sites, one of which sites is located at the interface between the two monomers (Figure
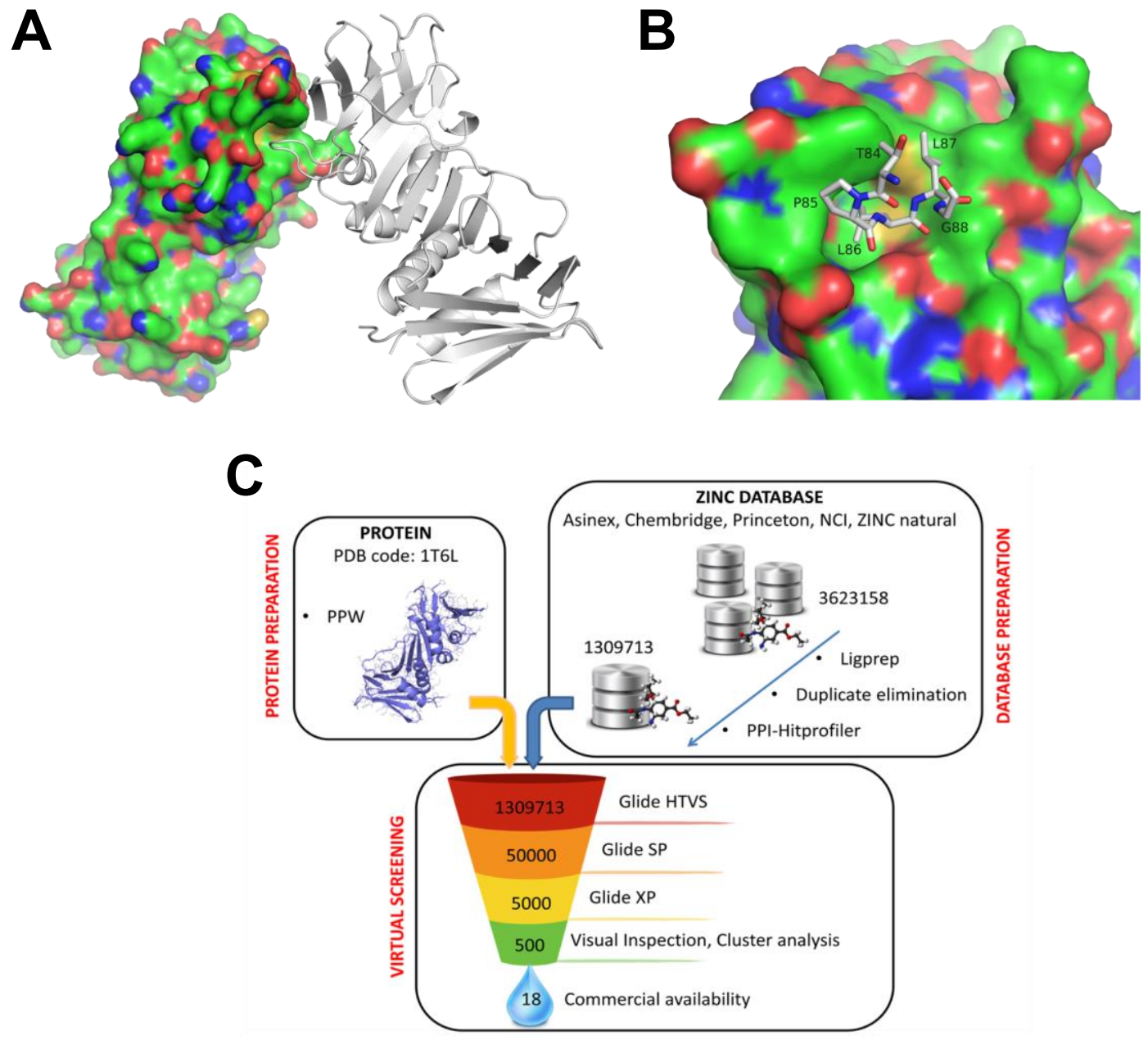

Figure 1. An in silico screening to identify SMs inhibiting ppUL44 dimerization. (A) Graphic representation of UL44(1-290) homodimers. One monomer is represented as surface, the other one as ribbons, with residues involved in the dimerization being shown as sticks. (B) Inset of the homodimerization interface. (C) Schematic overview of the virtual screening to identify SMs potentially disrupting UL44 homodimerization. The Glide software was used to dock molecules to the interface of the two monomers (PDB code: 1T6L). Three rounds of screening by were performed using the High throughput virtual screening (HTVS), Standard Precision (SP) and Extra Precision (XP) docking settings. After each docking, round the top-ranked molecules in term of docking score were selected for the following round. The resulting 500 molecules were further filtered by visual inspection, cluster analysis and, on the basis of their commercial availability, 18 compounds were selected for further studies.

1B). Such pocket has a druggability score (Dscore) of $\cong 0.8$ according to SiteMap (0.797) and it is therefore potentially druggable [44]. The key residues seem to be L87 and especially L86, which are located in a cavity formed by the residues F121, M123, M116, L93, C117, K101, T100, A118, L99, S96, D98 and P119 of the other monomer. Therefore, the center of the grid built for the docking calculation 
was set on M116 and such structure was used to screen about 1.3 million compounds from the ZINC database using the Glide software (Figure 1C). Eighteen of these molecules were purchased and used for further assays (Supplementary Figure S1 and Supplementary Tables 1 and 2).

3.2 Identification of compounds interfering with HCMV replication. SMs were subsequently screened for their ability to interfere with HCMV replication. In order to identify compounds active in the micromolar range, each SMs was tested at two different concentrations (10 and $100 \mu \mathrm{M})$, and GCV $(50 \mu \mathrm{M})$ was included as a positive control for inhibition of viral replication. After infection and compound treatment, cells were monitored by light microscopy daily for 7 days p.i. to evaluate cytopathic effect (CPE), presence of precipitates, and viral replication. At 7 days p.i., cells were lysed and the plates processed for fluorimetric quantification of the levels of viral replication relative to each condition. In parallel, MTT assays were performed with uninfected cells. At the lowest concentration tested $(10 \mu \mathrm{M})$, only one compound (A4) was not soluble and caused evident cytotoxicity, whereas two compounds (B3 and B6) inhibited viral replication (Figure 2A). On the other hand, at the highest concentration tested $(100 \mu \mathrm{M})$ several of the $18 \mathrm{SMs}$ formed visible precipitates and caused cell death, indicating poor solubility and toxicity, while two compounds (B1 and C6) impaired viral replication without markedly affecting cell viability (Figure 2B). In summary, our data showed that four SMs reduced viral replication in the absence of precipitates and evident cell cytotoxicity, to levels similar to those observed upon GCV treatment. Such inhibition was confirmed by microscopic analysis of infected cells, with a noticeable decrease in CPE and number and intensity of YFP-positive cells, to similar levels as GCV-treated cells (not shown).

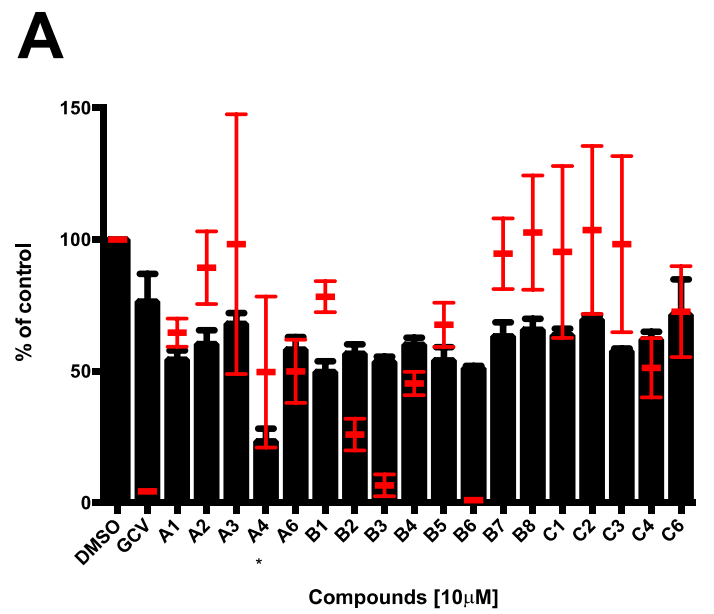

C

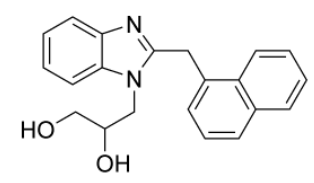

B1

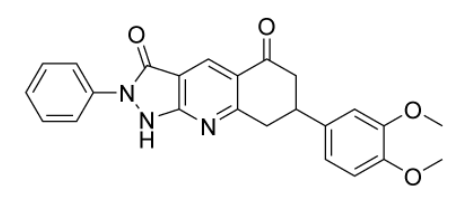

B3
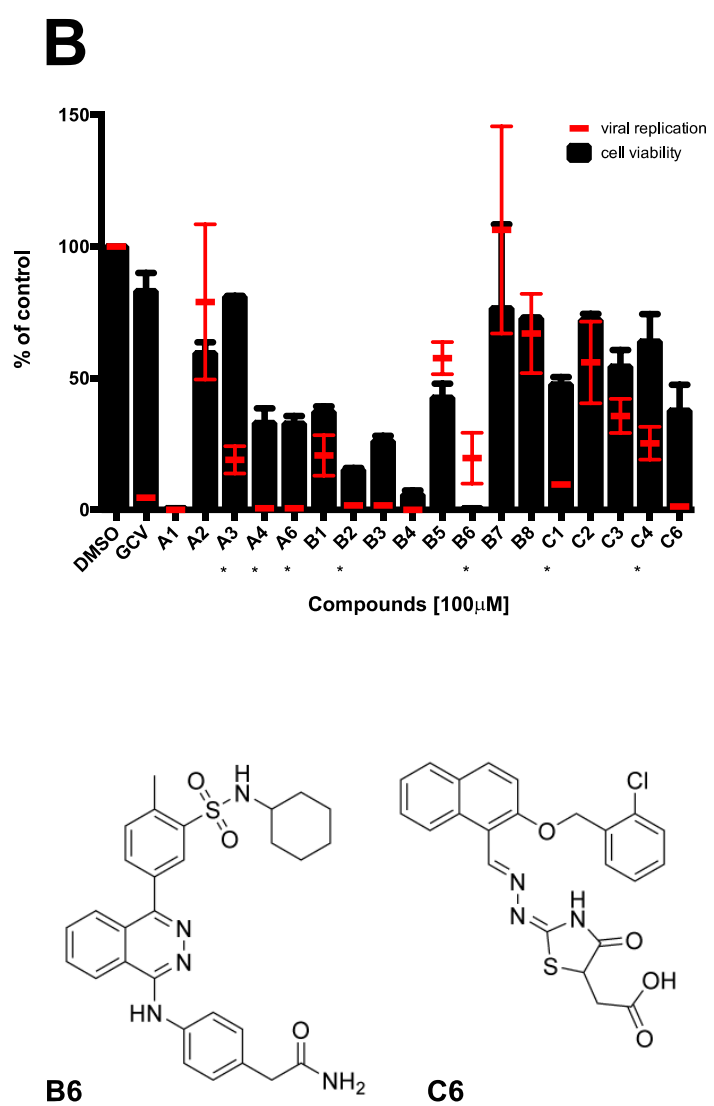

C6

Figure 2. Identification of compounds interfering with HCMV replication. MRC5 cells were infected with TB40-UL83-EYFP at an MOI of 0.03 IU/cell and treated with each SM either at concentration of $10 \mu \mathrm{M}$ (A) or 100 $\mu \mathrm{M}$ (B). In parallel, uninfected MRC5 cells were also treated for assessment of SMs cytotoxicity. Seven days post treatment, cells were processed for data acquisition and analysis as described in the Materials and Methods section. Mean YFP values relative to infected cells treated with the indicated SMs are expressed as a percentage 
of DMSO-treated cells (red bars). Cell viability was assessed by MTT assays, and data expressed as a percentage of DMSO-treated cells (black columns). The mean + standard error of the mean (SEM) relative to 3 independent experiments is shown. ${ }^{*}$ indicates the presence of precipitates. (C) The chemical structure of active molecules is shown.

3.3. Dose-dependent inhibition of HCMV replication. We then determined Effective Dose (ED50) and Cytotoxic Concentration ( $\mathrm{CC}_{50}$ ) values of each of the 4 SMs identified in our small-scale FRA-based screening (i.e. B1, B3, B6 and C6). To this end, we performed dose-response FRAs and MTT assays in MRC5 cells treated with increasing concentrations of each SM. Importantly, all tested SMs reproducibly inhibited viral replication in a dose-dependent manner, with ED50 values in the low micromolar range (Figure 3). As expected, GCV efficiently inhibited HCMV replication with a ED50 of $2.3 \pm 0.7 \mu \mathrm{M}$ and did not cause detectable cytotoxic effects at any concentration tested. Among the SMs tested B6 was the most potent compound and exhibited an ED50 slightly lower that that calculated for GCV $(2.5 \pm 0.7 \mu \mathrm{M})$. However, it was also endowed with considerable cytotoxicity $\left(\mathrm{CC}_{50}\right.$ of $\sim 10 \mu \mathrm{M}$ ), resulting in an SI $<5$. On the other hand, B3, the second most potent SM (ED50 of $4.2 \pm 2.4$ $\mu \mathrm{M})$, did not cause evident cytotoxicity up to $100 \mu \mathrm{M}$, and therefore had an SI > 20. C6 also exhibited low cytotoxicity, but was significantly less efficient in inhibiting HCMV replication than the other two SMs (ED50 of 16.5 $\pm 10.3 \mu \mathrm{M}$ ), and cell morphology appeared significantly altered upon microscopic evaluation (not shown). Finally, the effect of B1 on HCMV life cycle was evident only at high concentrations (ED50 of $86.7 \pm 10.3 \mu \mathrm{M}$ ).

GCV

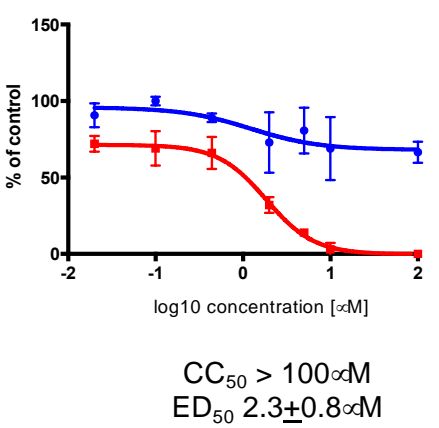

B6

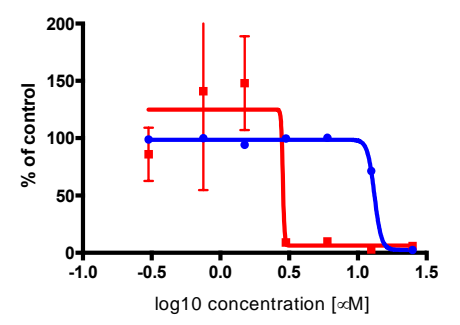

$\mathrm{CC}_{50} 10.7 \pm 2.3 \propto \mathrm{M}$

$\mathrm{ED}_{50} 2.1 \pm 0.6 \propto \mathrm{M}$
B1

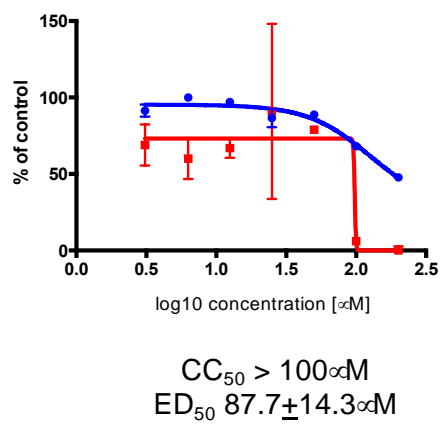

B3

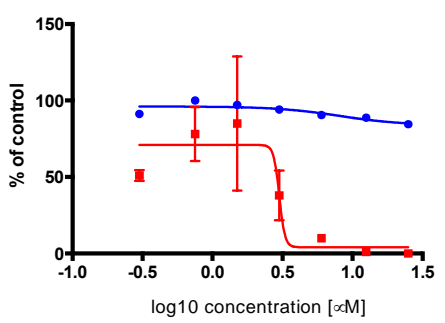

$\mathrm{CC}_{50}>100 \propto \mathrm{M}$

$\mathrm{ED}_{50} 4.2 \pm 2.4 \propto \mathrm{M}$

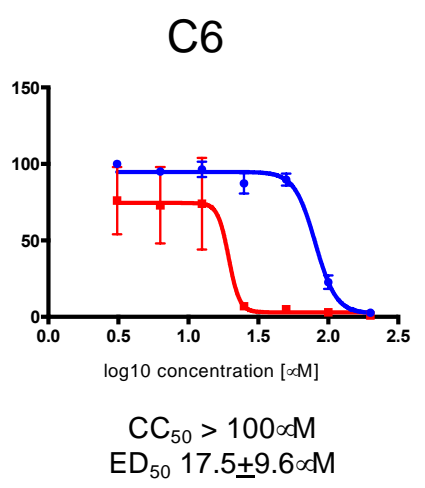

$\rightarrow$ cell viability

- viral replication

Figure 3. Determination of $\mathrm{ED}_{50}$ and $\mathrm{CC}_{50}$ values of SMs by FRA and MTT assay. MRC5 cells were infected with TB4-UL83-EYFP at an MOI of 0.03 IU/cell and treated with increasing concentrations of the indicated compounds. In parallel, uninfected MRC5 cells were also treated for assessment of SMs cytotoxicity. Seven days post treatment, cells were processed for data acquisition and analysis as described in the Materials and Methods section. Mean values YFP values relative to infected cells treated with the indicated compounds are expressed as a percentage of DMSO-treated cells (red squares). Cell viability was assessed by MTT assays, and data expressed as a percentage of DMSO treated cells (blue circles). For each compound, representative plots are 
shown, along with the cytotoxic concentration $50\left(C_{50}\right)$ and effective dose 50 (ED50) mean values + SEM of at least 4 independent experiments.

To further investigate the effects of each SM on cell viability and growth, we quantified the ATP levels in MRC5 cells treated with increasing concentrations, and cultured for different times (Figure 4). Results confirmed high toxicity of compound B6, which reduced ATP intracellular levels by more than $50 \%$ at $100 \mu \mathrm{M}$ already $24 \mathrm{~h}$ post treatment and by almost $100 \% 72 \mathrm{~h}$ post treatment. Importantly, cell treatment with C6 at $100 \mu \mathrm{M}$ similarly reduced ATP content by more than 30\% already after 24 h, whereas compounds B1 and B3 showed minimal effects at all time points analyzed. Overall, our data indicate that SM B3 might be specifically interfering with HCMV life cycle. The effect of B3 on HCMV AD169 was also assessed by PRA assays in HFF. In such experimental setting, SM B3 inhibited HCMV replication with an $\mathrm{ED}_{50}$ of $7.9 \pm 3.5 \mu \mathrm{M}$ (Figure 5).

A

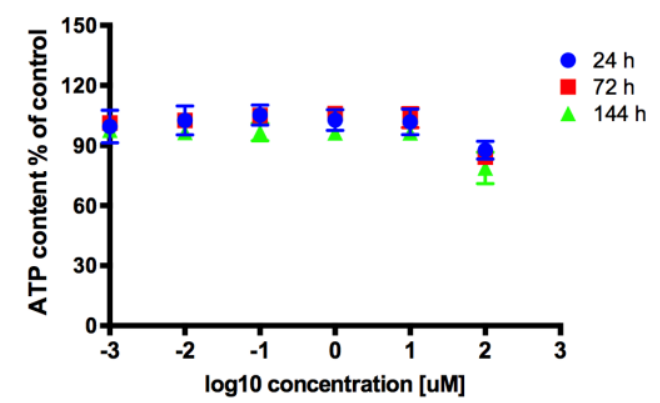

B6

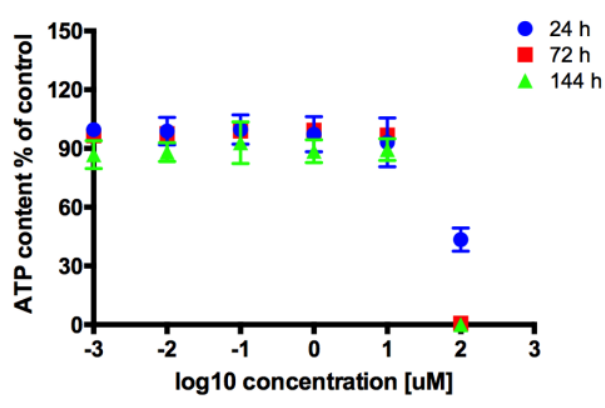

B3

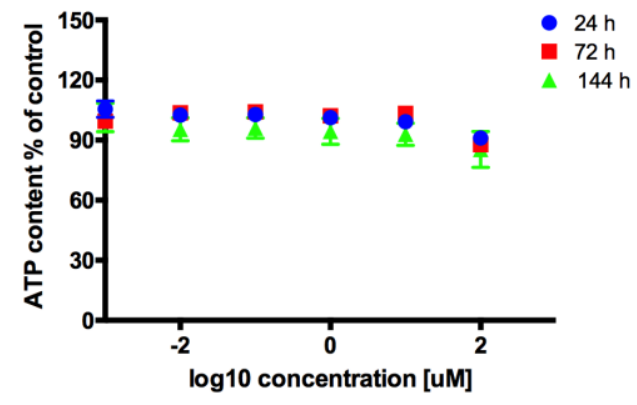

C6

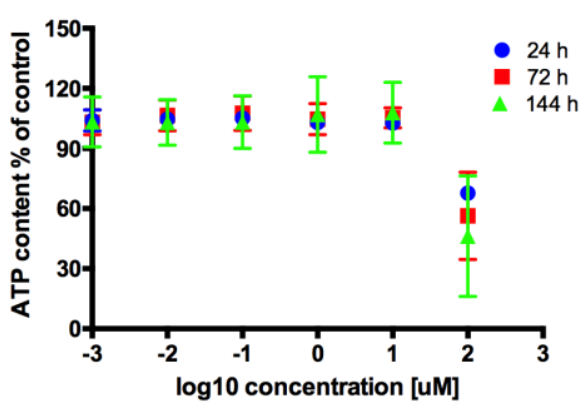

Figure 4. Effect on cell viability and proliferation of SMs inhibiting HCMV replication. MRC5 cells were treated with increasing concentrations of indicated compounds or with solvent only, as described in the Materials and Methods section. At the indicated time post treatments cells were processed for intracellular ATP quantification. Data shown are the mean + standard error of the mean relative to 3 independent experiments. 


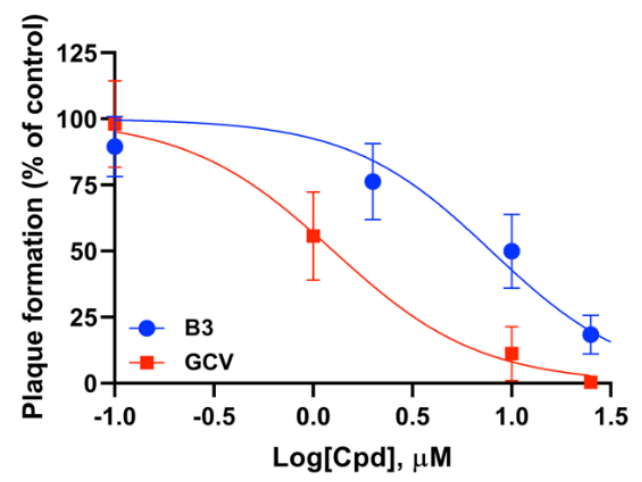

Figure 5. Inhibition of AD169 replication by B3 in PRA. Dose-response curves for B3 (blue) or GCV (red) were obtained by infecting HFF cells with HCMV AD169 and then treating them with different concentrations of the indicated compounds. Data shown are the means \pm standard deviation of four experiments performed in duplicate.

3.4 SM B3 inhibits replication of a HCMV GCV-resistant strain. An important characteristic of an antiviral interfering with ppUL44 dimerization would be its ability to inhibit replication of viral strains resistant to the currently used antivirals. To verify if compound B3 is endowed with such ability, we compared its ED50 against a recombinant reporter virus AD169-GFP, and its GCV-resistant counterpart AD169-GFP26, bearing the UL97 M460I substitution [47]. To this end, MRC5 cells were infected with of either AD169-GFP or AD169-GFP26 virus at MOI of $0.05 \mathrm{IU} /$ cell, treated with B3 or GCV for 1 week, and then viral replication was assessed by FRA. In parallel, infectious virus titers in cell culture supernatants were simultaneously quantified by VYRAs. FRA assays (Figure 6A, C and Table 1) revealed that GCV inhibited more efficiently replication of the AD169-GFP virus than of AD169-GFP26 (ED50 of 2.6 $\pm 0.8 \mu \mathrm{M}$ and $20.0 \pm 4.3 \mu \mathrm{M}$, respectively; $\mathrm{n}=5$ ), while AD169-GFP and AD169GFP26 appeared equally sensitive to $\mathrm{B} 3$ ( $\mathrm{ED}_{50}$ of $9.0 \pm 0.3 \mu \mathrm{M}$ and $21.1 \pm 4.7 \mu \mathrm{M}$, respectively; $\mathrm{n}=5$ ). Very similar results were obtained after quantification of viral progeny in VYRAs (Figure 6B, D). Indeed, GCV inhibited more efficiently viral production of AD169-GFP (ED50 of $0.5 \pm 0.47 \mu \mathrm{M} ; \mathrm{n}=3$ ) as compared of AD169-GFP26 (ED50 of $4.5 \pm 4.5 \mu \mathrm{M} ; \mathrm{n}=3$ ), whereas B3 did not (ED50 of 5.3+1.8 $\mu \mathrm{M}$ and $6.1+5.9 \mu \mathrm{M}$, respectively). Thus, B3 appears to efficiently impair replication of both GCV-sensitive and GCV-resistant HCMV. 
A

FRAs

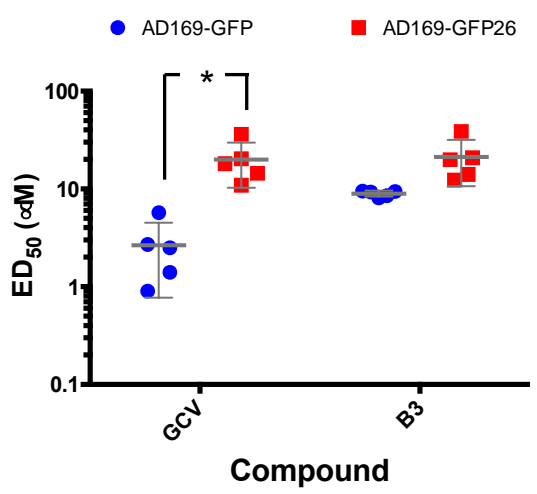

FRAs

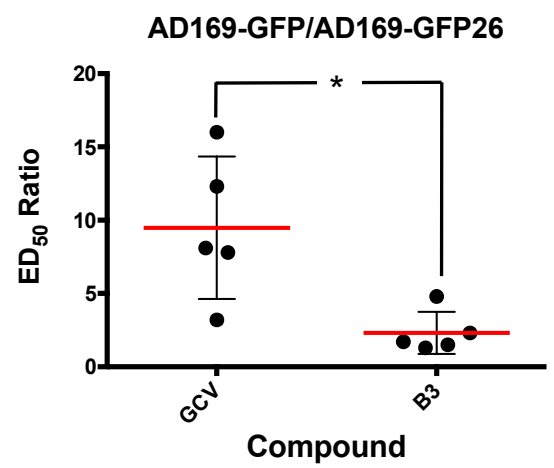

B

\section{virus yield}

- AD169-GFP

- AD169-GFP26

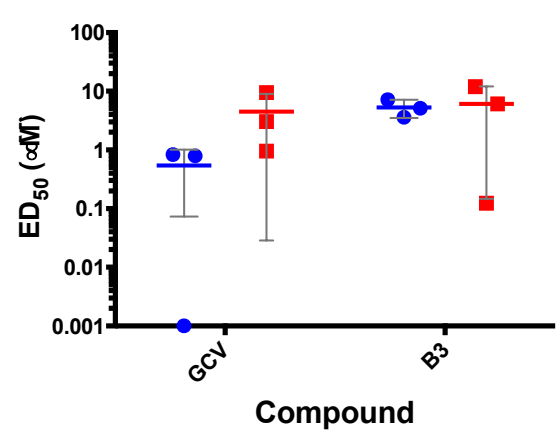

D

\section{virus yield}

AD169-GFP/AD169-GFP26

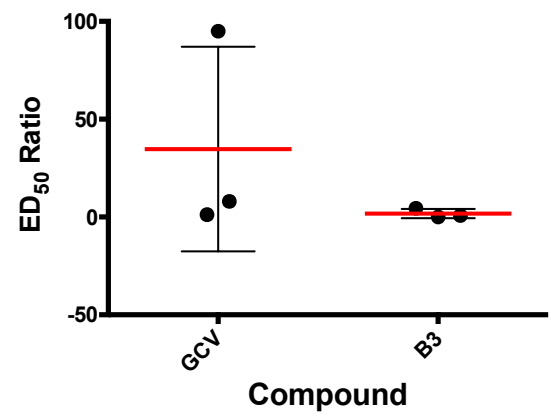

Figure 6. B3 efficiently inhibits replication of the GCV-resistant AD169-GFP26 virus. MRC5 were infected with either AD169-GFP virus or its GCV-resistant counterpart AD169-GFP26 at a MOI of 0.05 IU/cells and treated with increasing concentrations of the indicated compounds. At 7 days p.i., cells were lysed and plates processed for fluorimetric analysis using a plate reader $(A, C)$ and supernatants collected for virus yield reduction assays (B, D). For the latter experiments, MRC5 cells were infected with serial dilutions of supernatants derived from infected cells. At 7 days p.i., viral titers were calculated using the TCID50 method. Data from both assays were used to calculate the ED50 relative to the two viruses (A, B) as well as the ratio between the ED50 calculated for AD169-GFP26 and AD169-GFP (C, D), for both GCV and B3. Data shown are single measurements, means, and standard deviation of the mean relative to at least three independent experiments, along with the $\mathrm{p}$-value relative to the Student's t-test the indicated groups; ${ }^{*}: \mathrm{p} \leq 0.05$.

Table 1. Summary of FRA and VYA for AD169-GFP and AD169-GFP26

\begin{tabular}{lllllll} 
& \multicolumn{3}{c}{ FRA $(n=5)$ ED $50(\mu \mathrm{M})^{1}$} & \multicolumn{3}{c}{ VYRA $(n=3)$ ED $50(\mu \mathrm{M})$} \\
\cline { 2 - 7 } & AD169-GFP & AD169-GFP26 & ratio $^{2}$ & AD169-GFP & AD169-GFP26 ratio \\
\hline GCV & $2.6 \pm 0.8$ & $20.0 \pm 4.3$ & $9.7+2.3$ & $0.5 \pm 0.5$ & $4.5+4.5$ & $34.7 \pm 30.2$ \\
B3 & $9.0 \pm 0.3$ & $21.1 \pm 4.7$ & $2.4 \pm 0.6$ & $5.3 \pm 1.8$ & $6.1 \pm 5.9$ & $1.7 \pm 1-4$
\end{tabular}

${ }^{1} \mathrm{ED} 50$, effective dose 50, the dose of compound that reduces by $50 \%$ the fluorescence (FRA) or virus titers (VYRA). ${ }^{2}$ Ratio between values obtained for AD169-GFP26 and AD169-GFP. Data shown are mean and standard deviation of the mean relative to FRA (left panel) and VIRA (right panels) described in Figure 7. The numbers between brackets indicate the number of independent experiments for each B3 selectively impairs HCMV late gene expression. 
3.5 SM B3 selectively impairs HCMV late gene expression. In order to characterize the mode of action of B3, MRC5 cells were infected with AD169 at an MOI of $2 \mathrm{IU} / c e l l$ for $2 \mathrm{~h}$ and expression of immediateearly (IE1), early-late (UL44 and pp65), and late (pp28) proteins was assessed at different time points p.i. In the absence of HCMV antivirals, HCMV gene expression followed the typical pattern, with IE1 being readily detectable starting from 6 h p.i., ppUL44 from 12 h. p.i. and ppUL28 from 48 h p.i. (Figure 8 and Supplementary Fig. S2). As expected, neither GCV nor B3 treatment affected IE1 expression at 6 and $12 \mathrm{~h}$ p.i., indicating that the observed decrease in viral replication did not depend on an inhibition of activity on the major IE promoter (Figure 7A, B). Similarly, ppUL44 and pp65 levels were not affected up to $24 \mathrm{~h}$ p.i. (Figure 7C), confirming that IE function was not compromised. At $48 \mathrm{~h}$ p.i., a decrease in the expression of ppUL44 and -to a greater extent- of pp65 could be observed (Figure 7D). Importantly, both GCV and B3 treatment strongly inhibited pp28 expression at both $72 \mathrm{~h}$ and $96 \mathrm{~h}$ p.i. (Figure 7E, F). Densitometric analysis confirmed that GCV (Figure 8G) and B3 (Figure $8 \mathrm{H}$ ) inhibited HCMV gene expression with very similar kinetics, compatible with inhibition of viral DNA synthesis and interference with an early HCMV function, possibly disrupting ppUL44 homodimers.
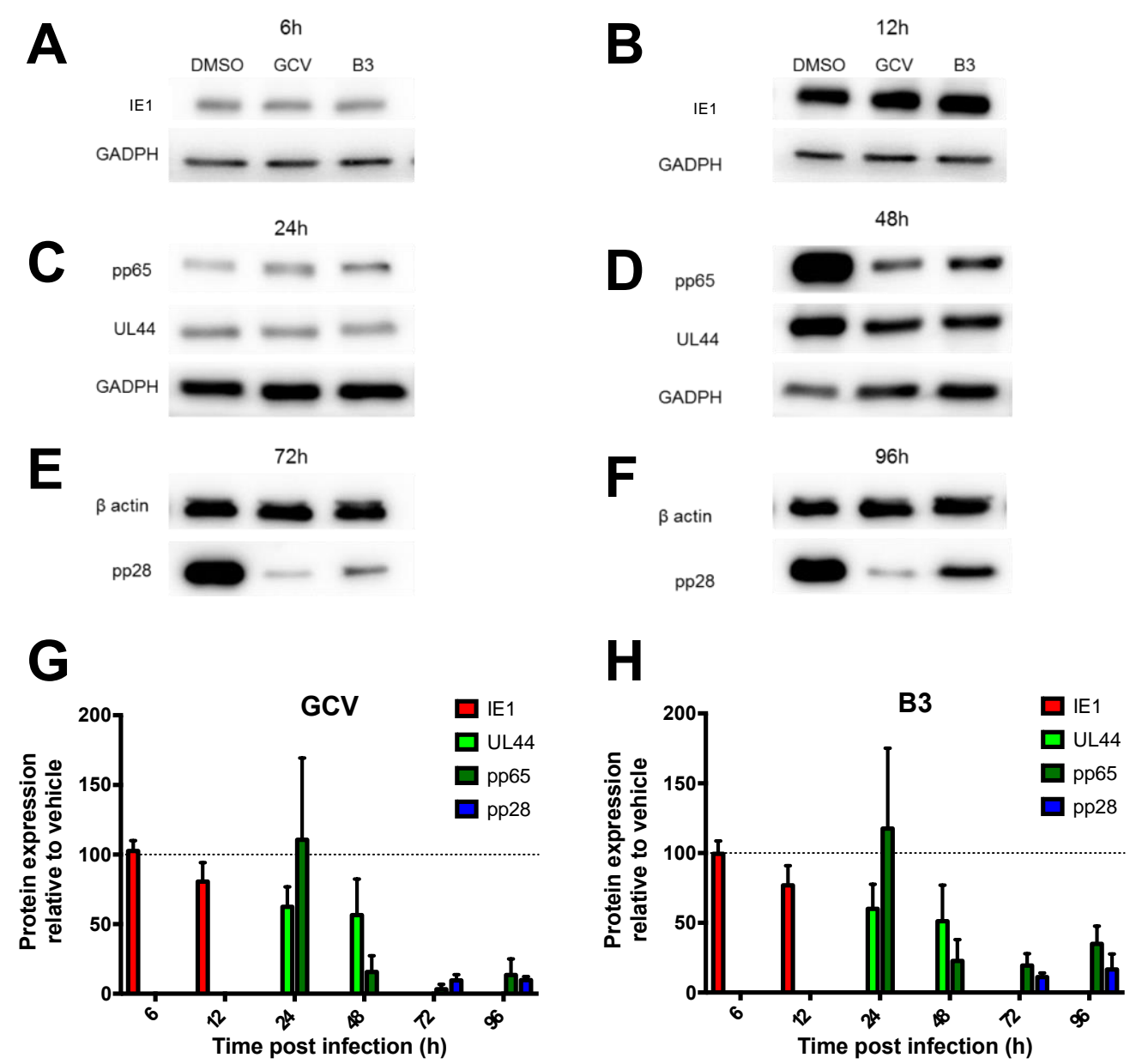

Figure 7. B3 specifically impairs early and late HCMV AD169 gene expression. MRC5 were infected with HCMV AD169 and treated as described in the Materials and Methods section. At the indicated time points p.i., cells were lysed and processed for Western Blotting to detect the expression of the immediate early IE1 antigen (A, B; at 6 and $12 \mathrm{~h}$ p.i.), the early-late antigens ppUL44 and pp65 (C, D; at 24 and $48 \mathrm{~h}$ p.i.), and the late antigen pp28 (E, F; at 72 and 96 h p.i.). GAPDH or $\beta$-actin were also detected as loading controls. (G, H): Loading controls were used to normalize signal intensity relative to each antigen after treatment with GCV (G) or B3 (H). Data shown are the mean + standard deviation of the mean relative to three independent experiments. 
Analysis of the predicted binding mode of B3 to ppUL44 revealed several hydrophobic interactions with pUL44 residues M116, C117, A118, P119, F121, M123, L99, L93 as well as two H-bond interactions with S96 (Figure 8).

\section{A}

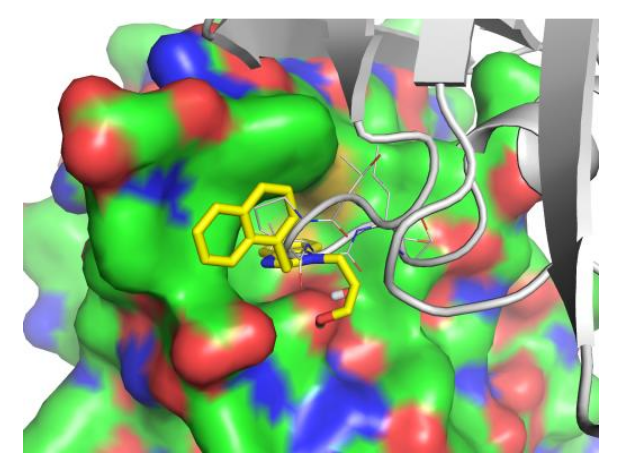

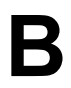

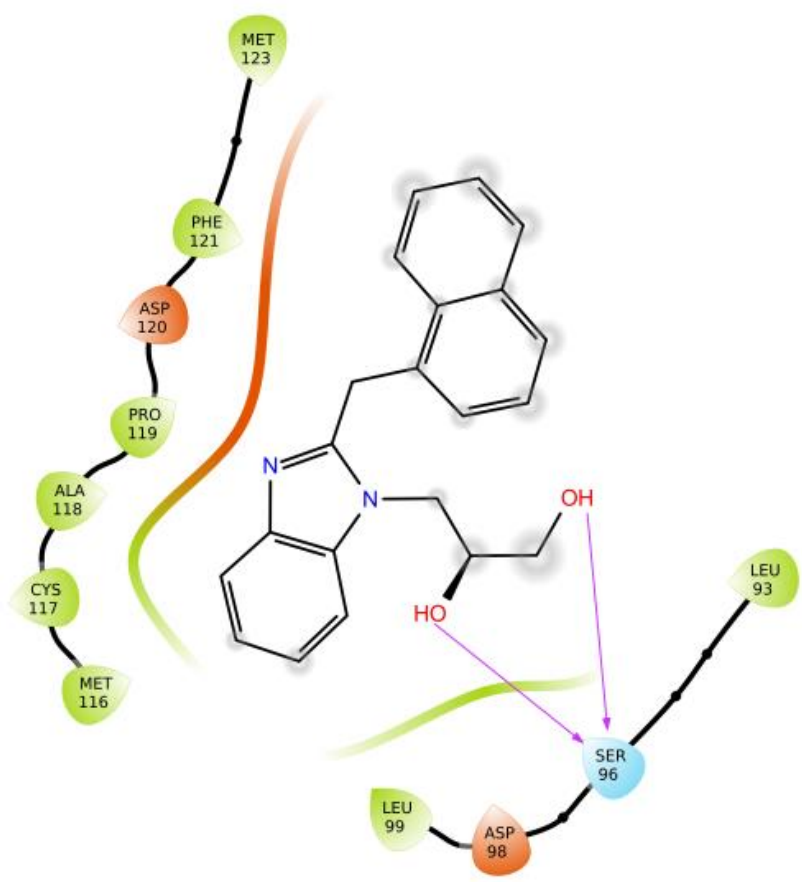

Figure 8. Analysis of the theoretical binding mode of B3 to ppUL44. A graphic representation of ppUL44(1290) homodimers in the presence of B3 is shown. (A): One monomer is represented as surface, the other one as ribbons, with residues involved in the dimerization being shown as sticks, whereas B3 is shown as yellow sticks. (B): 2D ligand interaction diagram of the theoretical binding mode for B3 is shown. Hydrogen bond interactions are shown as violet arrows. Positive and negative charged amino acids are represented in blue and red, respectively. Residues involved in hydrophobic or polar interactions are shown in green and light blue, respectively. Ligand-exposed fractions are indicated as a gray, circular shadow.

\section{Discussion}

Disruption of PPI interaction between viral proteins is becoming an increasingly attractive strategy for the antiviral drugs development. In this context, several studies identified peptides and SMs disrupting the interaction between Herpesviral DNA polymerase holoenzymes and their respective processivity factots [32, 51-54]. This is the first study exploring the possibility to directly target the dimerization of HCMV DNA polymerase accessory subunit ppUL44 as an antiviral strategy. The latter represents an interesting druggable target considering the interaction interface shown in the crystal structure of ppUL44(1-290), and the fact that single amino acid substitutions affecting dimerization in vitro also impaired dsDNA binding [16] and prevented oriLyt dependent DNA replication in trans-complementation assays [23]. Keeping this in mind, we performed a virtual screening aimed at identifying SMs inhibiting ppUL44 dimerization (Figure 1). Among the 18 SMs tested, one compound, i.e., B3, was able of inhibiting the replication of different HCMV strains at concentrations not affecting cell growth and viability (Figures 2-5), although with different efficacy. ED50 values ranged from 4.2 (FRA with TB4-UL83-EYFP) to $9.0 \mu \mathrm{M}$ (FRA with AD169-GFP), while those determined for GCV were comprised between 0.5 (VYRA) and 2.6 (FRA with AD169-GFP) $\mu M$ (see Table 2). The ED50 values calculated here for GCV are compatible

\begin{tabular}{llll}
\hline Assay & Virus & ED &
\end{tabular}




\begin{tabular}{|c|c|c|c|c|}
\hline & & & GCV & B3 \\
\hline FRA & $\begin{array}{l}\text { AD169-GFP } \\
\text { (1) }\end{array}$ & 5 & $2.6 \pm 0.8$ & $9.0 \pm 0.3$ \\
\hline FRA & TB4-UL83-EYFP & 6 & $2.3 \pm 0.7$ & $4.2 \pm 2.4$ \\
\hline PRA & AD169 & 4 & $1.3 \pm 0.9 \odot$ & $7.9 \pm 3.5$ \\
\hline VYRA & AD169-GFP & 3 & $0.5 \pm 0.5$ & $5.3 \pm 1.8$ \\
\hline
\end{tabular}

Table 2. Summary of ED 50 values calculated for GCV and B3 in this study. ED50 values from different assays (assay) and HCMV viruses (virus). The mean + standard deviation of the mean relative to the indicated number of independent experiments is reported. FRA, fluorescence reduction assay; PRA, plaque reduction assay; VYRA, virus yield reduction assay.

with those reported previously in the literature, with some variance being attributable to intrinsic differences between the different assays and viruses tested. For example, FRA with the TB40-UL83EYFP virus rely on the measurement of pp65 expression, which is expressed with an early-late kinetic, whereas the expression of the reporter gene in the AD169-GFP virus is under control of the IE promoter [47, 55]. Importantly, B3 also retained antiviral activity against a GCV-resistant strain, suggesting that its mechanism of action against HCMV differs from viral DNA polymerase inhibitors (Figure 7). We did not formally prove that B3 acts by disrupting the ppUL44 homodimer during viral infection, however, this mechanism is in agreement with the inhibition of HCMV gene expression in B3-treated cells starting from 48 p.i. and reaching its maximum with late gene expression at 72 and $96 \mathrm{~h}$ p.i.. This pattern of inhibition is very similar to that observed for GCV (see Figure 8 and Table 2) and is compatible with inhibition of viral DNA replication [56-58]. Although we did not formally prove here that B3 acts by disrupting the ppUL44 homodimer during viral infection, the fact that it inhibits HCMV gene expression starting from 48 p.i., and strongly inhibits late gene expression at 72 and $96 \mathrm{~h}$ p.i., in a very similar fashion to GCV (Figure 7 and Supplementary Figure 2) is compatible with inhibition of viral DNA replication [56-58].

Importantly, the effect of B3 reported here on HCMV replication is specific, since we recently demonstrated it did not affect either protein expression nor hepatitis $C$ virus replication (HCV) in Huh7-Lunet cells [59]. Despite B3 was less potent and more toxic than GCV, it might be useful as a starting platform for hit-to-lead optimization to develop more effective compounds as it has been performed with other PPI inhibitors endowed with antiviral activity against influenza virus [60-61]. Future work in our laboratory will be focused at characterizing in more detail the mechanism of action of B3 against HCMV, the isolation of resistant viral strains and the development of more potent molecules. Therefore, our results raise hopes in terms of potential use of HCMV dimerization inhibitors for the treatment of patients infected with drug-resistant HCMVs.

Supplementary Materials: The following are available online at www.mdpi.com/xxx/s1. Supplementary Figure S1. Molecular structure of purchased SMs. Supplementary Figure S2. B3 specifically impairs early and late HCMV AD169 gene expression. Table S1. List of compounds identified after the in silico screening, Table S2. List of compounds experimentally tested.

Author Contributions: Conceptualization, G.A. and F.F.; methodology, F.F., M.T, H.G., B.M. and G.A.; formal analysis, F.F, G.A., B.M., M.T. and H.G.; writing-original draft preparation, H.G., F.F. and G.A. writing-review and editing, G.A., A.L., B.M., H.G. and G. P.; supervision, G.A.; project administration, G.A.; funding acquisition, G.A., A.L., B.M. All authors have read and agreed to the published version of the manuscript.", please turn to the CRediT taxonomy for the term explanation. Authorship must be limited to those who have contributed substantially to the work reported.

Funding: This study was supported by Institutional research grants (ex 60\%), by the University of Padua (PRAT2013 grant CPDA130224/13 and BIRD grant ALVI_SID19_01 to G.A. and STARS Consolidator Grant FINDER to B.M.), by Associazione Italiana per la Ricerca sul Cancro, Italy (grant IG18855 to A.L.), by British Society for Antimicrobial Chemotherapy, UK (grant bsac-2018-0064 to A.L.), by Ministero dell'Istruzione dell'Università e della Ricerca, Italy (grant 2017KM79NN to A.L.), by Fondazione Cassa di Risparmio di Padova 
e Rovigo - Bando Ricerca Covid-2019 (Nr. 55777 2020.0162 - ARREST-COV: AntiviRal PROTAC-Enhanced Smallmolecule Therapeutics against COronaViruses" to A.L.).

Acknowledgments: Recombinant TB40-UL83-EYFP virus as well as AD169-GFP and AD169-GFP26 viruses were kindly provided by Micheal Winkler (Göttingen, Germany) and Manfred Marschall (Erlangen, Germany), respectively.

Conflicts of Interest: The authors declare no conflict of interest. The funders had no role in the design of the study; in the collection, analyses, or interpretation of data; in the writing of the manuscript, or in the decision to publish the results.

\section{Appendix A Extended Materials and Methods}

Preparation of small molecules (SMs) and Ganciclovir (GCV) stocks. Ganciclovir (GCV; Selleckchem, S1878) and small molecules (SMs), with a $>90 \%$ purity assessed by liquid chromatography mass spectrometry and high-performance liquid chromatography (Vitas-M Laboratory), were resuspended in $100 \%$ DMSO to obtain $20 \mathrm{mM}$ and $50 \mathrm{mM}$ stocks, respectively, and stored at $-20^{\circ} \mathrm{C}$ protected from light.

Plaque reduction assays. For plaque reduction assays (PRA) human foreskin fibroblast (HFF) cells were seeded in 24 -well plates $\left(2 \times 105\right.$ cells/well). The following day cells were infected at $37^{\circ} \mathrm{C}$ with 70 Plaque Forming Unit (PFU) of HCMV AD169 per well in DMEM containing FBS 5\%. At 2 h p.i., the inocula were removed, cells were washed, and media containing various concentrations of each compound, $5 \%$ FBS, and $0.6 \%$ methylcellulose were added. All compound concentrations were tested at least in triplicate. After incubation at $37^{\circ} \mathrm{C}$ for $10-11$ days, cell monolayers were fixed, stained with crystal violet, and viral plaques were counted.

Cell cytotoxicity assays. For MTT assays, MRC5 cells $\left(1.5 \times 10^{4}\right.$ cells/well $)$ were seeded in clear flat bottom 96-well tissue culture plates with low evaporation lids (Falcon, \#353072) in duplicate. After $24 \mathrm{~h}$, cells were treated with different concentrations of GCV or SMs, or solvent only. A number of wells containing only DMEM and no cells were also included for background correction. Seven days post-treatment, cells were processed for measurement of cell metabolic activity using 3-(4,5Dimethyl-2-thiazolyl)-2,5-diphenyl-2H-tetrazoliumbromid (MTT; Applichem, \#A2231) following the manufacturer's recommendations. After background subtraction, data were normalized to solventtreated controls and analyzed with Graphpad Prism (Graphpad Software Inc.). For intracellular ATP levels by means of CellTiter-Glo ${ }^{\circledR}$ assays (Promega), MRC5 cells were seeded in 96-Well Treated Multiwell Tissue Culture Plates, Opaque White plates (Falcon \#353296). After 24 h, cells were treated with different concentrations of GCV or SMs, or solvent only. A number of wells containing only DMEM and no cells were also included for background correction. At 24, 48 and $144 \mathrm{~h}$ post-treatment, cells were processed for measurement of ATP levels following the manufacturer's recommendations using a using a reader compatible with luminometric measurements (VICTOR X2 Multilabel Plate Reader, Perkin Elmer). After background subtraction, data were normalized to solvent-treated controls and analyzed with Graphpad Prism (Graphpad Software Inc.). The number of cells/well seeded was $1.5 \times 10^{4}, 4.5 \times 10^{3}$ and $1.5 \times 10^{3}$ cells for 24,72 and $144 \mathrm{~h} \mathrm{SMs} \mathrm{treatments,} \mathrm{respectively.}$

Analysis of HCMV gene expression by Western Blotting. MRC5 cells were seeded on 6-well flat bottom plates (6×105/well) with low evaporation lid (Falcon, \#353046). The following day, cells were either mock infected or infected with HCMV (strain AD169) at MOI of 2 IU/cell in DMEM at $37^{\circ} \mathrm{C}$. One hour p.i., cells were washed twice with PBS and medium containing either solvent only $(0.5 \%$ DMSO), GCV, or B3 at a concentration 6 times the ED50 as calculated for AD169-GFP in FRAs (16 or $50 \mu \mathrm{M}$, respectively), was added to each well. At different times p.i., cells were washed twice with PBS and lysed on ice with $250 \mu \mathrm{l}$ of RIPA buffer containing protease inhibitors (Tris- $\mathrm{HCl} 50 \mathrm{mM}, \mathrm{pH}$ 7.4, $150 \mathrm{mM} \mathrm{NaCl}, 1 \%$ Triton X-100 (v/v), 1\% sodium deoxycholate, 0.1\% SDS, $1 \mathrm{mM}$ EDTA, 17.4 $\mu \mathrm{g} / \mathrm{ml}$ phenylmethylsulfonyl fluoride, $2 \mu \mathrm{g} / \mathrm{ml}$ aprotinin, and $4 \mu \mathrm{g} / \mathrm{ml}$ leupeptin). The protein content in each sample was quantified using the Micro BCA Protein Kit assay (Thermo Fisher Scientific). 
Subsequently, $30 \mu \mathrm{g}$ of cell lysates were diluted in Laemmli sample buffer $(0.05 \mathrm{M}$ Tris- $\mathrm{HCl}, \mathrm{pH} 6.8$, $0.05 \%$ Bromophenol blue, $0.1 \mathrm{M} \mathrm{DTT}, 10 \%$ Glycerol [v/v], 2\% SDS) and boiled 5 minutes at $95^{\circ} \mathrm{C}$ before being loaded and electrophoretically separated on $8.5 \%$ polyacrylamide gels. Separated proteins were blotted on polyvinylidene fluoride (PVDF) membranes (GE Healthcare, \#RPN303F). Membranes were saturated with PBS containing 0.2\% Tween 20 and $5 \%$ milk (w/v) and incubated with the appropriate primary and secondary antibodies diluted in PBS containing $0.2 \%$ Tween 20 and $5 \%$ milk $(\mathrm{w} / \mathrm{v})$. Membranes were incubated with an enhanced chemiluminescence substrate (ECL Prime Western Blotting Detection Reagent, GE Healthcare, \#RPN2236). The following antibodies, diluted in PBS containing 0.2\% Tween20 and 5\% milk (w/v), were used: $\alpha$-His6 mAb (Sigma Aldrich, \#H-1029; 1:2,500), $\alpha$-IE1\&2 mAb (Virusys Corporation, \#P1251; 1:10,000), $\alpha$-UL44 mAb (Virusys Corporation, \#P1202-1; 1:100); $\alpha$-pp65 mAb (Virusys Corporation, \#CA003-1; 1:2,000); $\alpha$-pp28 (Abcam, \#ab6502; 1:10,000), rabbit $\alpha$-GADPH pAb (Santa Cruz Biotech, \#sc-25778; 1:5,000); mouse $\alpha$ $\beta$-Actin mAb (Sigma Aldrich, \# A5316 1:5,000); goat $\alpha$-mouse (Santa Cruz Biotech, \#sc-2055; 1:10,000) and $\alpha$-rabbit (Sigma Aldrich, \#A6154; 1:10,000) immunoglobulin Abs conjugated to horseradish peroxidase. Signals were acquired using an imaging system (Alliance Mini, Uvitech) and quantified using Image $\mathrm{J}(\mathrm{NIH})$.

\section{References}

1. Griffiths, P.; Baraniak, I.; Reeves, M., The pathogenesis of human cytomegalovirus. J Pathol 2015, 235, (2), 288-97.

2. Britt, W. J., Maternal Immunity and the Natural History of Congenital Human Cytomegalovirus Infection. Viruses 2018, 10, (8).

3. Alvisi, G.; Jans, D. A.; Camozzi, D.; Avanzi, S.; Loregian, A.; Ripalti, A.; Palu, G., Regulated transport into the nucleus of herpesviridae DNA replication core proteins. Viruses 2013, 5, (9), 2210-34.

4. Ertl, P. F.; Powell, K. L., Physical and functional interaction of human cytomegalovirus DNA polymerase and its accessory protein (ICP36) expressed in insect cells. J Virol 1992, 66, (7), 4126-33.

5. De Clercq, E., Selective anti-herpesvirus agents. Antivir Chem Chemother 2013, 23, (3), 93-101.

6. Lurain, N. S.; Chou, S., Antiviral drug resistance of human cytomegalovirus. Clin Microbiol Rev 2010, 23, (4), 689-712.

7. Drouot, E.; Piret, J.; Lebel, M. H.; Boivin, G., Characterization of multiple cytomegalovirus drug resistance mutations detected in a hematopoietic stem cell transplant recipient by recombinant phenotyping. Journal of clinical microbiology 2014, 52, (11), 4043-6.

8. Goldner, T.; Hewlett, G.; Ettischer, N.; Ruebsamen-Schaeff, H.; Zimmermann, H.; Lischka, P., The novel anticytomegalovirus compound AIC246 (Letermovir) inhibits human cytomegalovirus replication through a specific antiviral mechanism that involves the viral terminase. J Virol 2011, 85, (20), 10884-93.

9. Kim, E. S., Letermovir: First Global Approval. Drugs 2018, 78, (1), 147-152.

10. Jung, S.; Michel, M.; Stamminger, T.; Michel, D., Fast breakthrough of resistant cytomegalovirus during secondary letermovir prophylaxis in a hematopoietic stem cell transplant recipient. BMC Infect Dis 2019, 19, (1), 388 .

11. Lischka, P.; Michel, D.; Zimmermann, H., Characterization of Cytomegalovirus Breakthrough Events in a Phase 2 Prophylaxis Trial of Letermovir (AIC246, MK 8228). The Journal of infectious diseases 2016, 213, (1), 23-30.

12. Ripalti, A.; Boccuni, M. C.; Campanini, F.; Landini, M. P., Cytomegalovirus-mediated induction of antisense mRNA expression to UL44 inhibits virus replication in an astrocytoma cell line: identification of an essential gene. J Virol 1995, 69, (4), 2047-57. 
13. Gallo, M. L.; Dorsky, D. I.; Crumpacker, C. S.; Parris, D. S., The essential 65-kilodalton DNA-binding protein of herpes simplex virus stimulates the virus-encoded DNA polymerase. J Virol 1989, 63, (12), 5023-9.

14. Gibson, W.; Murphy, T. L.; Roby, C., Cytomegalovirus-infected cells contain a DNA-binding protein. Virology 1981, 111, (1), 251-62.

15. Weiland, K. L.; Oien, N. L.; Homa, F.; Wathen, M. W., Functional analysis of human cytomegalovirus polymerase accessory protein. Virus Res 1994, 34, (3), 191-206.

16. Appleton, B. A.; Loregian, A.; Filman, D. J.; Coen, D. M.; Hogle, J. M., The cytomegalovirus DNA polymerase subunit UL44 forms a C clamp-shaped dimer. Mol Cell 2004, 15, (2), 233-44.

17. Boccuni, M. C.; Campanini, F.; Battista, M. C.; Bergamini, G.; Dal Monte, P.; Ripalti, A.; Landini, M. P., Human cytomegalovirus product UL44 downregulates the transactivation of HIV-1 long terminal repeat. AIDS 1998, 12, (4), 365-72.

18. Silva, L. A.; Loregian, A.; Pari, G. S.; Strang, B. L.; Coen, D. M., The carboxy-terminal segment of the human cytomegalovirus DNA polymerase accessory subunit UL44 is crucial for viral replication. J Virol 2010, 84, (21), 11563-8.

19. Silva, L. A.; Strang, B. L.; Lin, E. W.; Kamil, J. P.; Coen, D. M., Sites and roles of phosphorylation of the human cytomegalovirus DNA polymerase subunit UL44. Virology 2011, 417, (2), 268-80.

20. Alvisi, G.; Jans, D.; Guo, J.; Pinna, L.; Ripalti, A., A protein kinase CK2 site flanking the nuclear targeting signal enhances nuclear transport of human cytomegalovirus ppUL44. Traffic 2005, 6, (11), 1002-1013.

21. Alvisi, G.; Marin, O.; Pari, G.; Mancini, M.; Avanzi, S.; Loregian, A.; Jans, D. A.; Ripalti, A., Multiple phosphorylation sites at the C-terminus regulate nuclear import of HCMV DNA polymerase processivity factor ppUL44. Virology 2011, 417, (2), 259-267.

22. Loregian, A.; Appleton, B. A.; Hogle, J. M.; Coen, D. M., Specific residues in the connector loop of the human cytomegalovirus DNA polymerase accessory protein UL44 are crucial for interaction with the UL54 catalytic subunit. J Virol 2004, 78, (17), 9084-92.

23. Sinigalia, E.; Alvisi, G.; Mercorelli, B.; Coen, D. M.; Pari, G. S.; Jans, D. A.; Ripalti, A.; Palu, G.; Loregian, A., Role of homodimerization of human cytomegalovirus DNA polymerase accessory protein UL44 in origin-dependent DNA replication in cells. J Virol 2008, 82, (24), 12574-9.

24. Komazin-Meredith, G.; Petrella, R. J.; Santos, W. L.; Filman, D. J.; Hogle, J. M.; Verdine, G. L.; Karplus, M.; Coen, D. M., The human cytomegalovirus UL44 C clamp wraps around DNA. Structure 2008, 16, (8), 1214-25.

25. Alvisi, G.; Roth, D. M.; Camozzi, D.; Pari, G. S.; Loregian, A.; Ripalti, A.; Jans, D. A., The flexible loop of the human cytomegalovirus DNA polymerase processivity factor ppUL44 is required for efficient DNA binding and replication in cells. J Virol 2009, 83, (18), 9567-76.

26. Jiang, C.; Hwang, Y. T.; Wang, G.; Randell, J. C. W.; Coen, D. M.; Hwang, C. B. C., Herpes simplex virus mutants with multiple substitutions affecting DNA binding of UL42 are impaired for viral replication and DNA synthesis. Journal of Virology 2007, 81, (21), 12077-12079.

27. Alvisi, G.; Jans, D.; Ripalti, A., Human cytomegalovirus (HCMV) DNA polymerase processivity factor ppUL44 dimerizes in the cytosol before translocation to the nucleus. Biochemistry 2006, 45, (22), 68666872.

28. Zarrouk, K.; Piret, J.; Boivin, G., Herpesvirus DNA polymerases: Structures, functions and inhibitors. Virus Res 2017.

29. Arkin, M. R.; Tang, Y.; Wells, J. A., Small-molecule inhibitors of protein-protein interactions: progressing toward the reality. Chemistry $\mathcal{E}$ biology 2014, 21, (9), 1102-14. 
30. Shimba, N.; Nomura, A. M.; Marnett, A. B.; Craik, C. S., Herpesvirus protease inhibition by dimer disruption. J Virol 2004, 78, (12), 6657-65.

31. Clackson, T.; Wells, J. A., A hot spot of binding energy in a hormone-receptor interface. Science 1995, 267, (5196), 383-6.

32. Loregian, A.; Marsden, H. S.; Palu, G., Protein-protein interactions as targets for antiviral chemotherapy. Rev Med Virol 2002, 12, (4), 239-62.

33. Celegato, M.; Messa, L.; Goracci, L.; Mercorelli, B.; Bertagnin, C.; Spyrakis, F.; Suarez, I.; Cousido-Siah, A.; Trave, G.; Banks, L.; Cruciani, G.; Palu, G.; Loregian, A., A novel small-molecule inhibitor of the human papillomavirus E6-p53 interaction that reactivates p53 function and blocks cancer cells growth. Cancer Lett 2019.

34. Muratore, G.; Goracci, L.; Mercorelli, B.; Foeglein, A.; Digard, P.; Cruciani, G.; Palu, G.; Loregian, A., Small molecule inhibitors of influenza A and B viruses that act by disrupting subunit interactions of the viral polymerase. Proc Natl Acad Sci U S A 2012, 109, (16), 6247-52.

35. Clackson, T.; Ultsch, M. H.; Wells, J. A.; de Vos, A. M., Structural and functional analysis of the 1:1 growth hormone:receptor complex reveals the molecular basis for receptor affinity. J Mol Biol 1998, 277, (5), 1111-28.

36. Kozakov, D.; Hall, D. R.; Chuang, G. Y.; Cencic, R.; Brenke, R.; Grove, L. E.; Beglov, D.; Pelletier, J.; Whitty, A.; Vajda, S., Structural conservation of druggable hot spots in protein-protein interfaces. Proc Natl Acad Sci U S A 2011, 108, (33), 13528-33.

37. London, N.; Raveh, B.; Schueler-Furman, O., Druggable protein-protein interactions--from hot spots to hot segments. Curr Opin Chem Biol 2013, 17, (6), 952-9.

38. Perkins, J. R.; Diboun, I.; Dessailly, B. H.; Lees, J. G.; Orengo, C., Transient protein-protein interactions: structural, functional, and network properties. Structure 2010, 18, (10), 1233-43.

39. Basse, M. J.; Betzi, S.; Bourgeas, R.; Bouzidi, S.; Chetrit, B.; Hamon, V.; Morelli, X.; Roche, P., 2P2Idb: a structural database dedicated to orthosteric modulation of protein-protein interactions. Nucleic Acids Res 2013, 41, (Database issue), D824-7.

40. Smith, M. C.; Gestwicki, J. E., Features of protein-protein interactions that translate into potent inhibitors: topology, surface area and affinity. Expert reviews in molecular medicine 2012, 14, e16.

41. Seetoh, W. G.; Abell, C., Disrupting the Constitutive, Homodimeric Protein-Protein Interface in CK2beta Using a Biophysical Fragment-Based Approach. J Am Chem Soc 2016, 138, (43), 14303-14311.

42. Frutos, S.; Rodriguez-Mias, R. A.; Madurga, S.; Collinet, B.; Reboud-Ravaux, M.; Ludevid, D.; Giralt, E., Disruption of the HIV-1 protease dimer with interface peptides: structural studies using NMR spectroscopy combined with [2-(13)C]-Trp selective labeling. Biopolymers 2007, 88, (2), 164-73.

43. Bannwarth, L.; Reboud-Ravaux, M., An alternative strategy for inhibiting multidrug-resistant mutants of the dimeric HIV-1 protease by targeting the subunit interface. Biochem Soc Trans 2007, 35, (Pt 3), 5514 .

44. Halgren, T. A., Identifying and characterizing binding sites and assessing druggability. J Chem Inf Model 2009, 49, (2), 377-89.

45. Falchi, F.; Caporuscio, F.; Recanatini, M., Structure-based design of small-molecule protein-protein interaction modulators: the story so far. Future Med Chem 2014, 6, (3), 343-57.

46. Bender, A.; Mussa, H. Y.; Glen, R. C.; Reiling, S., Similarity searching of chemical databases using atom environment descriptors (MOLPRINT 2D): evaluation of performance. J Chem Inf Comput Sci 2004, 44, (5), 1708-18. 
47. Marschall, M.; Freitag, M.; Weiler, S.; Sorg, G.; Stamminger, T., Recombinant green fluorescent proteinexpressing human cytomegalovirus as a tool for screening antiviral agents. Antimicrobial agents and chemotherapy 2000, 44, (6), 1588-97.

48. Hierholzer, J. C.; Killington, R. A., 2 - Virus isolation and quantitation. In Virology Methods Manual, Mahy, B. W. J.; Kangro, H. O., Eds. Academic Press: London, 1996; pp 25-46.

49. Mercorelli, B.; Luganini, A.; Celegato, M.; Palu, G.; Gribaudo, G.; Loregian, A., Repurposing the clinically approved calcium antagonist manidipine dihydrochloride as a new early inhibitor of human cytomegalovirus targeting the Immediate-Early 2 (IE2) protein. Antiviral Res 2018, 150, 130-136.

50. Sinigalia, E.; Alvisi, G.; Segre, C. V.; Mercorelli, B.; Muratore, G.; Winkler, M.; Hsiao, H. H.; Urlaub, H.; Ripalti, A.; Chiocca, S.; Palu, G.; Loregian, A., The human cytomegalovirus DNA polymerase processivity factor UL44 is modified by SUMO in a DNA-dependent manner. PLoS One 2012, 7, (11), e49630.

51. Loregian, A.; Coen, D. M., Selective anti-cytomegalovirus compounds discovered by screening for inhibitors of subunit interactions of the viral polymerase. Chemistry $\mathcal{E}$ biology 2006, 13, (2), 191-200.

52. Loregian, A.; Palu, G., Disruption of protein-protein interactions: towards new targets for chemotherapy. Journal of cellular physiology 2005, 204, (3), 750-62.

53. Palu, G.; Loregian, A., Inhibition of herpesvirus and influenza virus replication by blocking polymerase subunit interactions. Antiviral Res 2013, 99, (3), 318-27.

54. Chen, H.; Coseno, M.; Ficarro, S. B.; Mansueto, M. S.; Komazin-Meredith, G.; Boissel, S.; Filman, D. J.; Marto, J. A.; Hogle, J. M.; Coen, D. M., A Small Covalent Allosteric Inhibitor of Human Cytomegalovirus DNA Polymerase Subunit Interactions. ACS infectious diseases 2017, 3, (2), 112-118.

55. Straschewski, S.; Warmer, M.; Frascaroli, G.; Hohenberg, H.; Mertens, T.; Winkler, M., Human cytomegaloviruses expressing yellow fluorescent fusion proteins--characterization and use in antiviral screening. PLoS One 2010, 5, (2), e9174.

56. Hahn, F.; Hutterer, C.; Henry, C.; Hamilton, S. T.; Strojan, H.; Kraut, A.; Schulte, U.; Schutz, M.; Kohrt, S.; Wangen, C.; Pfizer, J.; Coute, Y.; Rawlinson, W. D.; Strobl, S.; Marschall, M., Novel cytomegalovirusinhibitory compounds of the class pyrrolopyridines show a complex pattern of target binding that suggests an unusual mechanism of antiviral activity. Antiviral Res 2018, 159, 84-94.

57. He, R.; Forman, M.; Mott, B. T.; Venkatadri, R.; Posner, G. H.; Arav-Boger, R., Unique and highly selective anticytomegalovirus activities of artemisinin-derived dimer diphenyl phosphate stem from combination of dimer unit and a diphenyl phosphate moiety. Antimicrobial agents and chemotherapy 2013, 57, (9), 4208-14.

58. Weekes, M. P.; Tomasec, P.; Huttlin, E. L.; Fielding, C. A.; Nusinow, D.; Stanton, R. J.; Wang, E. C.; Aicheler, R.; Murrell, I.; Wilkinson, G. W.; Lehner, P. J.; Gygi, S. P., Quantitative temporal viromics: an approach to investigate host-pathogen interaction. Cell 2014, 157, (6), 1460-72.

59. Elbadawy, H. M.; Abdul, M. I. M.; Aljuhani, N.; Vitiello, A.; Ciccarese, F.; Shaker, M. A.; Eltahir, H. M.; Pala, G.; Di Antonio, V.; Ghassabian, H.; Del Vecchio, C.; Salata, C.; Franchin, E.; Ponterio, E.; Bahashwan, S.; Thabet, K.; Abouzied, M. M.; Shehata, A. M.; Parolin, C.; Calistri, A.; Alvisi, G., Generation of Combinatorial Lentiviral Vectors Expressing Multiple Anti-Hepatitis C Virus shRNAs and Their Validation on a Novel HCV Replicon Double Reporter Cell Line. Viruses-Basel 2020, 12, (9).

60. Trist, I.M.L., Nannetti, G., Tintori, C., ...Loregian, A., Botta, M. 4,6-Diphenylpyridines as Promising Novel Anti-Influenza Agents Targeting the PA-PB1 Protein-Protein Interaction: Structure-Activity Relationships Exploration with the Aid of Molecular Modeling. Journal of Medicinal Chemistry, 2016, 59(6), pp. 2688-2703. 
61. Nannetti, G., Massari, S., Mercorelli, B., Bertagnin, C., Desantis, J., Palù, G., Tabarrini, O., Loregian, A. Potent and broad-spectrum cycloheptathiophene-3-carboxamide compounds that target the PA-PB1 interaction of influenza virus RNA polymerase and possess a high barrier to drug resistance. Antiviral Research 2019, 165:55-64. 